\title{
AVALIAÇÃO FENÓTIPICA E PRODUTIVA DE CULTIVARES CRIOULAS DE MILHO PARA A REGIÃO DE SÃO JOÃO DE PETRÓPOLIS, SANTA TERESA-ES
}

\author{
Renan Garcia Malikouski ${ }^{1}$ \\ Felipe Pereira Dal'Col ${ }^{2}$ \\ Rafael Vago Gonzales ${ }^{3}$ \\ Rafael Costa de Sant'Ana ${ }^{4}$ \\ Rafael Zucateli da Vitoria ${ }^{5}$ \\ Hediberto Nei Matiello ${ }^{6}$ \\ Francisco Braz Daleprane ${ }^{7}$
}

Resumo: O cultivo intenso de milho híbrido vem provocando o fenômeno conhecido como erosão genética, tornando-se importante a realização de trabalhos que visem caracterizar cultivares crioulas de milho a fim de indicar aos agricultores de cada região as variedades que mais se adaptem a sua realidade, além de fornecer informações relevantes aos programas de melhoramento. Sendo assim, o presente trabalho teve como objetivo caracterizar quatro cultivares crioulas de milho para a região de São João de Petrópolis, município de Santa Teresa - ES. O experimento foi realizado no Instituto Federal do Espirito Santo campus Santa Teresa, as variedades crioulas utilizadas foram: Aliança, Fortaleza, Cateto e Cunha, incluindo também o híbrido AG 1051 e a cultivar Incaper 203. Foram avaliadas as seguintes variáveis: altura de planta, altura de inserção de espiga, número de espigas por planta, ângulo foliar, diâmetro de colmo e produtividade. Observou-se que as cultivares crioulas apresentaram desempenho semelhante ou até superior em muitos parâmetros, evidenciando a possibilidade de cultivo dessas variedades crioulas atualmente.

Palavras-chave: Agricultura familiar; Programas de melhoramento; Zea mays L.

\footnotetext{
1 Instituto Federal do Espírito Santo - IFES, Campus Santa Teresa, Santa Teresa, ES, Brasil. E-mail: renan_malikouski@hotmail.com.

2 Instituto Federal do Espírito Santo - IFES, Campus Santa Teresa,Santa Teresa, ES, Brasil. E-mail: felipepdalcol@gmail.com.

3 Instituto Federal do Espírito Santo - IFES, Campus Santa Teresa,Santa Teresa, ES, Brasil. E-mail: rafaelvg2012@gmail.com.

${ }^{4}$ Instituto Capixaba de Pesquisa, Assistência Técnica e Extensão Rural - INCAPER, Centro Regional de Desenvolvimento Rural -Centro Norte, Laboratório de Fisiologia Vegetal e Pós-Colheita, Linhares, ES, Brasil. Emai: santanaagronomia@gmail.com.

${ }^{5}$ Universidade Federal do Espírito Santo - UFES, Centro Universitário Norte do Espírito Santo - CEUNES, São Mateus, ES, Brasil. E-mail: zucateli_rafael@hotmail.com.

6 Instituto Federal do Espírito Santo - IFES, Campus Santa Teresa, Santa Teresa, ES, Brasil. E-mail: hedibertonm@ifes.edu.br.

7 Instituto Federal do Espírito Santo - IFES, Campus Santa Teresa,Santa Teresa, ES, Brasil. E-mail: franciscobd@ifes.edu.br.
} 